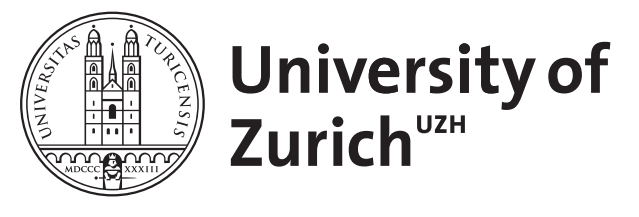

\title{
One goal for all the sciences?
}

Tietz, Sarah

\begin{abstract}
SummaryIn numerous writings Philip Kitcher argues against the thesis that understanding nature or searching for truth in general are goals that are shared by all the sciences. Neither do the sciences aim for common distinctive truths, such as natural laws. Thus, the question is: can the sciences be characterized as sciences by one of their goals? According to Kitcher this seems possible. The sciences, so he claims, aim for unification. In this paper I shall argue that unification should not be understood as an aim but rather as a method the sciences use depending on the specific problems they pursue. Therefore, it seems, there is not one goal for all the sciences.
\end{abstract}

DOI: https://doi.org/10.1515/cpt-2009-9406

Posted at the Zurich Open Repository and Archive, University of Zurich ZORA URL: https://doi.org/10.5167/uzh-155398

Journal Article

Published Version

Originally published at:

Tietz, Sarah (2009). One goal for all the sciences? Conceptus Zeitschrift für Philosophie, 38(94):61-72. DOI: https://doi.org/10.1515/cpt-2009-9406 


\title{
One Goal for All the Sciences?
}

\author{
Sarah Tietz
}

\begin{abstract}
Summary: In numerous writings Philip Kitcher argues against the thesis that understanding nature or searching for truth in general are goals that are shared by all the sciences. Neither do the sciences aim for common distinctive truths, such as natural laws. Thus, the question is: can the sciences be characterized as sciences by one of their goals? According to Kitcher this seems possible. The sciences, so he claims, aim for unification. In this paper I shall argue that unification should not be understood as an aim but rather as a method the sciences use depending on the specific problems they pursue. Therefore, it seems, there is not one goal for all the sciences.
\end{abstract}

In 'The Ends of the Sciences', Philip Kitcher sets out to show that the whole scientific context - including the so-called "context of resolution" - is socially embedded and therefore value-laden. I propose to use his line of argument in order to address the question of whether there is one end or goal that is shared by all the sciences.

Considering the diversity of the sciences, there do not seem to be many likely candidates. Biologists study life and living organisms, physicists the nature of matter and its motion through space-time, and political scientists describe and analyse political systems. Subject matters and their respective guiding questions could not be more diverse. This is not surprising, of course, for the diversity of the sciences is reflected in their different questions and, hence, in their different goals. However, it does not seem farfetched to assume that, among all the various goals of sciences, there is at least one that is shared by them all. I am thinking of truth. All sciences, or so it seems, seek truth.

Its obvious character notwithstanding, truth cannot figure as the 
common goal for all sciences, for, as Kitcher rightly points out, the slogan "'Seek truth!' is plainly incomplete." First of all, a question has to be framed. Only then is "the goal of finding a true answer [...] a sensible one." (Kitcher 2004: 212.) That is, there are always particular types of truth that sciences look for. Accordingly, our question has to be whether there are certain types of truth, which all sciences look for. As a matter of fact, such types of truth do seem to be available. For sciences seek the possibility of prediction and intervention in broad areas. That is, they need statements that explain individual special cases as instances of a common type. Therefore, it seems, sciences need natural laws. We could say, then, that the goal of the sciences is not the search for truth, for this is too general, but the search for a distinctive type of truth, namely natural laws.

However, it cannot easily be taken for granted that natural laws are indeed the goal of all the sciences. For, as is well known, there are many sciences such as history, political sciences, philosophy, and even natural sciences such as biology, whose findings do not take the form of natural laws. Of course, this need not be an argument against the thesis that sciences aim at finding natural laws. After all, one could say that those disciplines that do not or cannot share this end simply do not count as sciences; and for disciplines such as philosophy, sociology or literature, there are numerous scholars who do indeed share this opinion.

However, this view might be nothing but mere stipulation. What we need is a separate argument, one that shows why it is only the quest for natural laws that qualifies a discipline to be a science. Yet there is also an alternative strategy: in order to examine the thesis that only those disciplines that aim at finding natural laws can be counted as sciences, we might examine and evaluate its (tacit) assumptions. Kitcher points out the following: on the one hand, "it supposes that there's some general project of understanding nature," and on the other hand, "it assumes that there's some manageable collection of laws that can be appreciated by human beings (or by a recognizable idealization of ourselves) and that will make possible the general project." (Kitcher 2004: 
213-14) These two assumptions go together with a third, which is almost trivial: at least one science is needed that has the collection of natural laws as its main goal. If other disciplines, those whose generalizations do not take the form of natural laws, are to count as sciences, too, then they would need to be reducible, in one way or another, to this special science. One science that aims at discovering natural laws is, of course, physics. Accordingly, physicalism would be the position to be held.

All three assumptions, however, present well-known difficulties. Firstly, after the appearance of "There is no Question of Physicalism" by Crane and Mellor, at the latest, physicalism appears to be no longer tenable. (Crane \& Mellor 1990) For physicalism faces the following dilemma: Who decides what is to count as a physical object? An obvious answer is, of course, physicists; but which physicists do we mean: the exponents of the current, or of an idealized, complete, future physics? If the first are meant, then physicalism is presumably false. For, it is not very likely that present-day physics has identified all the physical entities. If, however, an idealized, complete future physics is meant, then physicalism amounts to something trivial. After all, an idealized and complete physics would necessarily pick out all basic entities, of whatever kind they might be. Yet, how are we to exclude the possibility that, among these basic entities, there are also numbers or qualia; entities that, as far as we know, are not objects of natural laws?

But even if we accept physicalism, there are further problems with the assumption that the sciences aim at finding natural laws. For it presupposes that it is possible for sciences both "to fall into a finite number of clusters, each of which can be subsumed under a finite number of basics laws" and to "extend beyond the areas of inquiry that have so far emerged in the actual history of the sciences to cover all the phenomena." As a matter of fact, if these things were possible, the assumption, that there is some collection of laws which can be appreciated by human beings (or by a recognizable idealization of ourselves) and which makes possible the general project of understanding nature, could be sustained. 
(Kitcher 2004: 214) Yet, as Kitcher rightly remarks, "once the unity-of-science picture has been discarded, there's no basis for thinking that the clusters of laws (even assuming we can always find them) won't proliferate indefinitely." (Kitcher 2004: 215)

A third problem presented by these assumptions lies in the idea of a general project of understanding nature. For, the slogan "Understand nature!" is as incomplete and as meaningless as the slogan "Seek truth!" (Kitcher 2004: 215). In addition, there is the question of what is meant by "nature"? It is obvious that attempts to answer this question present the same dilemma as physicalism.

Therefore, it seems we have good reasons to abandon the thesis that only those disciplines whose goal is the discovery of natural laws can count as sciences. Do we have an alternative end, then, that might characterize all the sciences? Having dismissed the above-mentioned ends Kitcher, himself, makes the following suggestion. Sciences, so he claims, have a common ideal: they all aim at unity. Contrary to appearance, this is not a lapse back to the unity-of-science movement: for Kitcher, as well, there is and can be no unity of science.

Nevertheless, he claims, sciences reflect a regulative ideal, namely "the ideal of finding as much unity as we can by discovering perspectives from which we can fit a large number of apparently disparate empirical results into a small number of schemata." (Kitcher 1999: 339) Thus, sciences exemplify what Kitcher calls "modest unificationism". This unificationism is modest in at least two ways: on the one hand, as just, seen, it maintains that sciences cannot be unified for the reasons mentioned in the beginning. Therefore, on the other hand, this unificationism allows for different unifying schemes for explaining and predicting various aspects of nature; schemes, that "aren't integrable into any overarching grand theory." (Kitcher 2004: 347). What holds all sciences together, therefore, is not that they are reducible to one special science but that they are all modestly unificationist. All sciences aim at unification. Unification is their regulative ideal. In what follows, I want to challenge this idea. Using an argument 
recently provided by Ingo Brigandt, who refers to the relatively new discipline of evolutionary-developmental biology, I want to suggest that unification should not be understood as an aim in itself but rather as a method. (Brigandt 2010) Unification, or the combination of concepts, disciplines or theories, or so I want to argue, is a method whose application depends only on the problem pursued. The idea is to strike a balance between (modest) unificatory approaches and pluralistic approaches according to which sciences are, and always will be, a disunified plural. (Dupré 1993)

First of all, a few words on evolutionary-developmental biology, short: evo-devo. As the words already suggest, evo-devo aims at an integration of the long separated disciplines of evolutionary biology and developmental biology. This enterprise is motivated by the fact that, in addition to adaptation and speciation, there are other questions about evolution, such as the question for phenotypic evolvability or the question of the evolutionary origin of body plans and novel structure, which cannot be answered by referring merely to neo-Dawinism. Here, an appeal to developmental biology is required. There are several reasons for this. One important reason is that the genes that are involved in important early developmental events are shared across large groups of animals (mammals and insects, for instance). Therefore, it seems obvious that phenotypic evolution cannot be explained by merely referring to specific changes in genes. What appears to be needed instead is an explanation of evolutionary changes in the regulation of gene activations. What appears to be needed is knowledge of development (Hall \& Olson 2003).

Appearances to the contrary, notwithstanding, evo-devo should not be seen as a simple synthesis of evolutionary and developmental biology, with developmental genetics providing the link. For, many evo-devo problems, such as accounting for the origin of novel structures, require "integrating knowledge from many different disciplines, including population genetics, developmental biology, phylogeny, palaeontology, morphology, theoretical biology, and ecology." (Brigandt 2010: 298; also: Hall 2007; Wagner 2007) 
Now, how and, above all, why are all these disciplines integrated? Let us, as Brigandt does, take a look at the explanation of evolutionary novelties. Evolutionary novelties have to be distinguished from variations. While a variation is a gradual change of an existing feature in an ancestral species, an evolutionary novelty, on the other hand, is described by Ernst Mayr as "any newly acquired structure or property that permits the performance of a new function." (Mayr 1963: 602) That is, evolutionary novelties are qualitatively new morphological structures or function features in a group of organisms that did not exist in an ancestral species. Examples are the vertebrate jaw, feathers and flight in birds, the turtle carapace, and paired fins in fish and their transformation into limbs in amphibians.

What seems clear is that for an explanation of these novelties phylogeny is extremely relevant. For, what is needed is a determination of the particular phylogenetic junctures at which characters were transformed and novelties arose in evolution. Thus, any explanation of the origin of novelties needs phylogentic trees. Now, these trees were usually based on an analysis of classical characters, such as morphological structures. But nowadays, they are also inferred from molecular data, such as gene sequences. Thus, the problem is to integrate both approaches. This is challenging since there are several cases where each supports a different phylogeny. Despite attempts to combine "both kinds of data (by so-called total evidence approaches), there are currently no generally agreed upon methods of determining how to weigh the contribution of classical and molecular information." (Brigandt 2010: 299f.) However, both approaches are important in order to explain novelties. This holds as well for palaeontology. It supports phylogeny in the explanation of novelties, in that its research into past organisms can provide information about the ancestral states of characters. And even more importantly, palaeontology determines if there are structural intermediates between the state and the descendant. On that basis it can suggest particular morphological changes that may have constituted the origination of the novel feature. 
Disciplines such as ecology and biogeography are also indispensable in this context. Without them it would be impossible to get an exhaustive explanation of the evolution of novelties. For, of course, not only the novelties themselves but also the transitional states before them must have been positively favored by, or at least compatible with, natural selection. Therefore, in addition to having knowledge of the existence of structural intermediates, knowledge of the changes in geographical and ecological conditions undergone by a certain species is necessary.

But here again we have two levels of explanation: the microevolutionary level of neo-Darwinism that focuses on change in gene frequencies within a species and the palaeontological macroevolutionary level of large-scale trends that involves many species. Once again, both levels have to be integrated. "For while the advent of major novelties (such as the evolution of limbs) or whole body plans involves macroevolutionary events, at the same time it has to be made plausible how the advent of a phenotypic novelty can be consistent with modes of genetic change within populations." (Brigandt 2010)

But why, one might ask, is neo-Darwinian evolutionary theory, with its use of population genetics, not in a position to account for the origin of novelties, by itself? Brigandt provides the following reasons. (Brigandt 2010: 300f.) Firstly, if the task is to explain how and why phenotypic variation could have been produced, at all, neo-Darwinism cannot provide an exhaustive answer. For, neo-Darwinism explains phenotypic change based on natural selection. And natural selection, as is well-known, acts on heritable phenotypic variation that already exists. Thus any theory that appeals to natural selection alone faces difficulties when it comes to the explanation of novelties. This is not surprising, of course, for explanations based on natural selection are by their nature retrospective. The explanation of new things, on the other hand, must involve some prospective or developmental aspects. Of course, there is some knowledge of which mechanisms produce genotypic variation, but this is not a question to be answered in this context. For, we want to know "how genotypic variation translates 
into phenotypic variation - which is the domain of developmental biology." (Brigandt 2010: 300f.; also Kirschner \& Gerhart 2005) Another reason Brigandt appeals to is that not every genetically produced phenotypic variation is developmentally possible. Thus there are genetically possible phenotypic variations that are more or less likely to occur than others. This is the case, or so Brigandt holds, because, contrary to the generation of phenotypic variants, "genetic variation is produced in a largely random and unbiased fashion." (Brigandt 2010: 301) Therefore, he concludes, whichever variations occur must be developmentally grounded.

I think Brigandt's conclusion is right, but not for the reason he provides. Whether the production of genetic variations follows certain patterns or, as Brigandt holds, is carried out in a random and unbiased fashion, is highly controversial. Of course, molecular biologists try to prove the former. However, it is not necessary to decide on these matters in order for the thesis to be true that whichever phenotypic variation occurs it must be developmentally grounded. It is sufficient to appeal to the obviously uncontroversial claim that not every genetically produced phenotypic variation is developmentally possible. From this it follows almost trivially that it is developmental biology that can, or rather, must explain which variation was possible, which evolved as a consequence and which not.

A third reason why neo-Darwinism alone cannot account for evolutionary novelties is that many novelties, such as the evolution of feathers from reptilian scales, "involve a breaking up of developmental or functional constraints that prevailed in the ancestral lineage." (Müller \& Wagner 2003: 220) That is, although both feathers and scales, have certain developmental roots in common, it does not follow that feathers evolved as a variation, that is in a smooth transition, from scales. This is so because feathers are not within the normal mutational range of scales. Accordingly scales must have been governed by certain developmental constraints, which, at some point, were broken. And since an account of novelties has to explain firstly, "how ancestral developmental constraints could have been and were broken thereby leading to 
the emergence of the novelty", and secondly, "how the new structure was developmentally integrated with other structures," the main appeal in that account must be to developmental biology - not to neo-Darwinism. (Brigandt 2010: 302; see also Müller \& Newman 1999)

The fourth and last reason against the explanatory priority of neo-Darwinism that I want to mention is that many novelties are mere by-products of selection, that is, of adaptive evolution. There are cases where there was no selection for certain tissues getting close to each other. Here, natural selection is, of course, causally involved, but it does not carry the explanatory force in an account of novelty.

The moral of this is that features within organisms must be explanatorily important for the explanation of novelties. Thus, an account of novelties cannot rely on neo-Darwinistic accounts alone but rather is in need of knowledge from many different fields, such as phylogeny, palaeontology, ecology, biogeography, developmental biology and neo-Darwinism. And of course, knowledge of functional morphology is, also, of importance. For the evolutionary origin of novel structures includes also function features. As just seen, the case of explaining novelties, as many other cases as well, does not allow for a reduction to neo-Darwinism. The same holds for any other of the above-mentioned disciplines. One important reason is that structures on different levels sometimes evolve independently of one another. Therefore, as Brigandt rightly points out, "biologists have to find the various natural kinds or units that are relevant for a particular developmental or evolutionary explanation." (Brigandt 2010: 303)

The necessary failure of reduction should not lead us to the opinion that evo-devo is just a case of pluralism. Its combination of different methods and approaches is not a mere accident. On the contrary, accounting for the evolutionary origin of novelties makes it necessary to integrate different theoretical models and modes of explanations. Evo-devo needs both microevolutionary theories of population genetics and macroevolutionary models of palaeontology. Both scientific approaches have to be combined 
in this case. The same holds for explanations of developmental biology and for those of functional morphology. They, too, have to be integrated with neo-Darwinian modes of explanation. Of course, as just seen, developmental biology and functional morphology are more explanatory fundamental than neo-Darwinism in the explanation of novelties. But, and this is the important point, there is nothing intrinsic about both disciplines that makes them explanatory fundamental. (Brigandt 2010: 304)

Now, why this extensive discussion of the explanation of novelties by evo-devo? Because I think this example shows that unification is not an aim in itself. That there is no general linear ordering of more or less explanatory fundamental theories or disciplines does not only show that there is no hierarchy among sciences; a fact Kitcher himself argued for. It also shows that Brigandt is right in that epistemic relations between different disciplines are rather complex and, what is of importance, the relative contribution and explanatory fundamentality of each approach "depends on and varies with the particular problem." (Brigandt 2010: 305) And each problem has its own criteria of explanatory adequacy. (Love 2008) Thus, what amount of integration or unification is needed depends on those criteria. They determine the overall shape necessary for an explanation. That is, they determine which theoretical and/or empirical ideas are relevant for solving a particular problem. Thus, the criteria of explanatory adequacy - together with the specific problem - not only determine the amount of unification needed, they determine if a unification of different methods is necessary at all. Therefore, unification, as I said, is not an aim in itself, but rather a method that might be needed for a certain aim, namely for the aim of solving a complex scientific problem. Thus, I completely agree with Brigandt: In contrast to Kitcher's "ideal of finding as much unity as we can" (Kitcher 1999: 339), he recommends "the ideal of finding as much unity as scientists need in order to solve a scientific problem." (Brigandt 2010: 207)

If this is right, then the sciences are not distinguished from nonsciences by having the aim of unification as a regulative ideal. 
This, together with the discussion at the beginning of this paper, suggests, then, that the sciences do not share one common end. And what is more, even a single science does not have specific ends. In the words of Richard Feynman (Nobel Prize-winner for physics): "Science is like sex. Sure, it may give some practical results, but that's not why we do it." Thus, the sciences are not distinguishable by their aims - either from one another and from non-sciences. Neither do they aim for truth in general, nor for natural laws, nor for unification.

\section{References}

Brigandt, I.: Beyond Reduction and Pluralism. Toward an Epistemology of Explanatory Integration in Biology. In: Erkenntnis, 73, p. 295-311, 2010.

Crane, T./ Mellor, T. H.: There is no Question of Physicalism. In: Mind, 99, p. 185-206, 1990.

Dupré, J.: The Disorder of Things: Metaphysical Foundations of the Disunity of Science. Cambridge MA: Harvard University Press, 1993.

Hall, B. K./ Olson, W. M. (eds): Keywords and Concepts in Evolutionary Developmetal Biology. Cambridge MA: Harvard University Press, 2003.

Hall, B. K./ Olson, W. M.: Tapping Many Sources. The Adventitious Roots of Evo-Devo in the Nineteenth Century. In: Laubichler, M. D./ Maienschein, J. (eds), From Embryology to Evo-Devo. A History of Developmental Evolution, p. 467-497, Cambridge MA: MIT Press, 2007.

Kirschner, M./ Gerhart, J.: The Plausibility of Life: Resolving Darwin's Dilemma. New Haven: Yale University Press, 2005.

Kitcher, P.: Unification as a Regulative Ideal. In: Perspectives on Science, 7 3, p. 337-348, 1999. 
- The Ends of the Sciences. In: The Future of Philosophy, Oxford: Clarendon Press, 2004.

Love, A. C.: Explaining Evolutionary Innovation and Novelty. Criteria of Adequacy and Multidisciplinary Prerequisites. In: Philosophy of Science, 75, p. 874-886, 2008.

Mayr, E.: Animal Species and Evolution. Cambridge MA: Belknap-Harvard University Press, 1963.

Müller, G. B./ Newman, S. A.: Generation, Integration, Autonomy. Three Steps in the Evolution of Homology. In: Bock, G. R./ Cardew, G. (eds), Homology, p. 65-73, 1999.

Müller, G. B./ Wagner, G. P.: Innovation. In: Hall, B. K./ Olson, W. M. (eds), Keywords and Concepts in Evolutionary Developmetal Biology, p. 218-227, Cambridge MA: Harvard University Press, 2003.

Wagner, G. P.: The Current State and the Future of Developmental Evolution. In: Laubichler, M. D./ Maienschein, J. (eds), From Embryology to Evo-Devo. A History of Developmental Evolution, p. 525-545, Cambridge, Mass.: MIT Press, 2007.

Philosophisches Seminar

Universität Zürich

Zürichbergstrasse 43

8044 Zürich, Schweiz

tietz@philos.uzh.ch 